\title{
Research on Scientific Research Efficiency Evaluation and Countermeasures of Undergraduate Universities in Shanxi Province
}

\author{
Wen Zhao \\ Shanxi University of Finance \& Economics \\ College of Management Science and Engineering \\ Taiyuan, China
}

\author{
Ya-hui Lu* \\ Shanxi University of Finance \& Economics \\ College of Management Science and Engineering \\ Taiyuan, China
}

\begin{abstract}
As an important position for scientific research, it is of great significance to analyze the efficiency of scientific research in universities. After constructing the input and output evaluation index system, this paper adopts DEA model to evaluate the efficiency of 27 universities in Shanxi Province. The evaluation results show that the research efficiency of undergraduate universities in Shanxi Province is acceptable, but there are great individual differences, and many universities have great room for improvement. Some undergraduate universities invest a lot of resources and their scale decreases, which leads to the waste of resources. And some universities are in the state of insufficient resource investment. In view of these evaluation results, this paper puts forward four suggestions, such as expanding the talent team, making rational use of resources, giving full play to the "characteristics" of universities, and establishing an evaluation system, which provides feasible suggestions for the future rational development of scientific research efficiency of undergraduate universities in Shanxi Province.
\end{abstract}

Keywords-Shanxi Province; Research efficiency; DEA; undergraduate universities

\section{INTRODUCTION}

Colleges and universities are important places for scientific research output, and scientific research results have an important impact on the economic development of the relevant areas. The industry-university-research chain decides that the scientific research level of a region's institutions of higher learning will affect its future economic development. In addition to providing talent training, colleges and universities can also provide high-quality scientific research results. Highquality scientific research results can be applied to the actual production and life of the region, thus driving regional economic development. However, education is a scarce resource. How to exert the limited resources to a greater value is related to the development prospect of regional universities and the development of the region itself. In order to obtain sustainable high-quality scientific research results, undergraduate universities in Shanxi Province need to continuously adjust whether the scientific research resources input is reasonable or not and the output. In other words, they need to pay constant attention to the efficiency of scientific research. Therefore, selecting scientific, reasonable and effective methods to evaluate the scientific research efficiency of Shanxi Province's undergraduate colleges and universities is conducive to the rational and optimal allocation of higher education resources in Shanxi Province and to promote the benign development of regional colleges and universities.

Based on this, more and more scholars begin to study the efficiency of scientific research in universities. From the perspective of evaluation methods, DEA, AHP and fuzzy comprehensive evaluation are mainly adopted in the academic circle to evaluate the scientific research ability of Chinese universities from different perspectives. In terms of research content, the research on evaluation of scientific research ability of colleges and universities can be divided into the following three aspects according to different research decision-making units: first, research on departments and disciplines of colleges and universities. Jun CAI (2018) [1] used the DEA evaluation method to construct the evaluation model of the internal faculty operating efficiency of the university, and explored the internal relationship between the research efficiency of each secondary department and the scientific research development of the university. Ying Wang (2007) [2] used the principal component analysis method in the study to construct an evaluation system based on input indicators and outputs. In the empirical research, CCR and CCRMP models after DEA improvement were adopted to select management schools of 8 universities for analysis, and corresponding evaluation results were obtained. Secondly, research on the research efficiency of some kinds of universities. XiaoHua Song (2019)[3] defined the concept of research universities in China in their research and constructed an evaluation system of scientific research benefits by selecting corresponding indexes for research universities. LianBao Qiao (2015)[4], based on the assumption of constant return on scale, built a joint DEA model considering the consumption of common resources and used to evaluate the comprehensive efficiency of scientific research and teaching in colleges and universities, and analyzed 32 "985" colleges and universities. Finally, regional research efficiency research. HuiQing Zhang (2015)[5] divided colleges and universities in China according to provinces in their research, and selected data from 2003 and 2011 for DEA model analysis, constructed a perfect evaluation system and made an empirical analysis. TianZuo Liu(2018)[6] uses data envelopment analysis (DEA) to empirically study the input and output performance of universities in different regions of China from 2009 to 2016, and then uses the Tobit model to explore 
the main factors affecting the performance of scientific research input and output in regional universities.

Through comprehensive review and analysis of previous research results and contents, it can be found that data envelopment analysis (DEA) has developed rapidly in all aspects due to its advantages and characteristics in recent decades. However, there is still some research space. For example, from the perspective of regional research, there are few researches on the research efficiency of universities in Shanxi Province, and these researches are relatively old. Therefore, in order to fill the research gap, DEA evaluation is conducted on the scientific research efficiency of colleges and universities in Shanxi Province during the past six years (20122017). Therefore, it puts forward some ideas and plans to improve the efficiency of scientific research in colleges and universities, and provides references for the development of colleges and universities in Shanxi Province.

\section{ReseARCh Method Design, Model SELECtiON AND INDEX DATA OF SCIENTIFIC RESEARCH EFFICIENCY OF UNIVERSITIES IN SHANXI PROVINCE}

\section{A. Evaluation model and method}

Data envelopment analysis (DEA) method is one of the main methods used in efficiency evaluation at present. This method has been applied in many fields and is a nonparametric test analysis method for multiple inputs and multiple outputs. This method USES operational research and mathematical programming to analyze and evaluate related problems. The basic DEA model CCR model can only evaluate the comprehensive efficiency, and cannot further analyze the results of scientific research efficiency. Because the CCR model assumes a fixed scale benefit in the calculation, that is, the change form is equal to the size of the input. However, in actual production and life, the scale benefit varies unequally, and the scale return decreases or increases with the amount of input in the production process. There are limitations. However, when the super-efficient DEA model computes more DMU decision making units and the input-output is segmented, the differences in decision making units are easy to be exaggerated. Because this paper is to analyze and compare the relative efficiency of undergraduate universities in Shanxi Province, it is necessary to consider the effect of scale benefit among universities on the evaluation results. Therefore, the BCC model of DEA is selected in this paper for efficiency evaluation, which is conducted on the basis of fully considering the evaluation criteria of comprehensive efficiency, scale efficiency and technical efficiency. This paper tries to provide reasonable and effective guiding Suggestions for Shanxi undergraduate universities to optimize the allocation of resources and improve the efficiency of scientific research.

\section{B. Research index selection and data processing description}

The complete index system for university research institutions was designed in 1988, which was commissioned by the former national education commission. With the continuous development and improvement of the research on the evaluation of scientific research efficiency in colleges and universities, more and more scholars have been trying to establish the evaluation index system of scientific research efficiency in colleges and universities in recent years. Input indicators mainly include: human resources configuration, total funds and projects of science and technology, scientific research personnel, scientific and technological investment expenditures on science and technology, science and technology activities, the internal spending of funds and other fund by the total number of subjects of science and technology, science and technology project of science and technology input number, subject of science and technology research and development expenditures, full-time equivalent staff, government funds, enterprises and institutions entrusted funds. Output indicators mainly include: scientific and technological achievements, scientific communication, scientific research reward and income, and number of academic papers published, focusing on publishing scientific books, intellectual property authorization number, scientific and technological achievements transfer amount, monographs, foreign paper number, other national journal paper number, number of appraisal results, technology transfer, patent sale revenue, technology transfer, the actual income.

The selection of evaluation units in this paper is 27. Generally speaking, the data envelopment analysis in the evaluation index number selection should be adapted to the number of evaluation unit, so in the selection of evaluation index, this paper is based on the experience of previous scholars, input and output indicators of evaluation units are screened by factor analysis, with full-time equivalent expenses within budget as input variables, the number of scientific publications, the number of foreign and national publications, achievement award, the technology transfer of the actual income as output index. See table I

TABLE I. INPUT INDEX AND OUTPUT INDEX

\begin{tabular}{|c|c|c|}
\hline $\begin{array}{c}\text { The index } \\
\text { type }\end{array}$ & $\begin{array}{c}\text { Index } \\
\text { number }\end{array}$ & Specific indicators \\
\hline \multirow{2}{*}{$\begin{array}{c}\text { Input } \\
\text { indicators }\end{array}$} & $\mathrm{X} 1$ & Full time equivalent personnel \\
\cline { 2 - 3 } & $\mathrm{X} 2$ & $\begin{array}{c}\text { Internal expenditure on science and } \\
\text { technology funds }\end{array}$ \\
\hline \multirow{4}{*}{$\begin{array}{c}\text { Output } \\
\text { indicators }\end{array}$} & $\mathrm{Y} 1$ & $\begin{array}{c}\text { The number of scientific and } \\
\text { technological works published }\end{array}$ \\
\cline { 2 - 3 } & $\mathrm{Y} 2$ & $\begin{array}{c}\text { Publication volume of foreign and } \\
\text { national publications }\end{array}$ \\
\cline { 2 - 3 } & $\mathrm{Y} 3$ & Results in the prize \\
\cline { 2 - 3 } & \multicolumn{2}{|c|}{$\begin{array}{c}\text { The actual income from technology } \\
\text { transfer that year }\end{array}$} \\
\hline
\end{tabular}

\section{EFFICIENCY MEASUREMENT AND EVALUATION}

This paper selects 27 undergraduate universities in Shanxi Province as evaluation units. In order to avoid the error caused by the extreme value of some data and the inaccuracy of the data, the data are averaged in this paper. The data of input and output of 6 years are calculated on average so that each input index of each university can get an average of 6 years, and the data after average processing is analyzed for data envelopment. Data are input into DEAP2.1 for processing. Period choice 1, input index choice 2, output index choice 4, output orientation and multi-stage DEA calculation are selected. The calculation results are shown in the Table II. 
TABLE II. OPERATION RESULTS OF EACH DECISION UNIT

\begin{tabular}{|c|c|c|c|}
\hline Firm & CRSTE & VRSTE & $\begin{array}{l}\text { Scale } \\
\text { Scal }\end{array}$ \\
\hline Shanxi university & 0.765 & 0.797 & 0.96 \\
\hline Taiyuan University of Technology & 1 & 1 & 1 \\
\hline $\begin{array}{l}\text { Taiyuan university of science and } \\
\text { technology }\end{array}$ & 0.784 & 0.793 & 0.989 \\
\hline North university of china & 0.471 & 0.476 & 0.991 \\
\hline Shanxi agricultural university & 0.655 & 0.659 & 0.994 \\
\hline Shanxi medical university & 0.359 & 0.63 & 0.57 \\
\hline Changzhi medical college & 0.347 & 0.401 & 0.865 \\
\hline Shanxi normal university & 0.76 & 0.833 & 0.912 \\
\hline Taiyuan normal university & 0.679 & 0.719 & 0.945 \\
\hline Shanxi Datong university & 0.697 & 0.869 & 0.802 \\
\hline Jinzhong college & 0.913 & 1 & 0.913 \\
\hline Changzhi college & 0.758 & 0.857 & 0.885 \\
\hline Yuncheng institute & 0.578 & 0.658 & 0.879 \\
\hline Xinzhou normal university & 0.717 & 0.873 & 0.822 \\
\hline $\begin{array}{c}\text { Shanxi University of Finance and } \\
\text { Economics }\end{array}$ & 0.522 & 1 & 0.522 \\
\hline $\begin{array}{c}\text { Shanxi college of traditional } \\
\text { Chinese medicine }\end{array}$ & 1 & 1 & 1 \\
\hline Luliang college & 0.614 & 1 & 0.614 \\
\hline Taiyuan institute & 0.795 & 1 & 0.795 \\
\hline $\begin{array}{l}\text { Shanxi institute of applied science } \\
\text { and technology }\end{array}$ & 0.57 & 1 & 0.57 \\
\hline $\begin{array}{c}\text { School of business, Shanxi } \\
\text { university }\end{array}$ & 0.518 & 1 & 0.518 \\
\hline $\begin{array}{l}\text { School of modern science and } \\
\text { technology, Taiyuan university of } \\
\text { technology }\end{array}$ & 0.57 & 1 & 0.57 \\
\hline $\begin{array}{l}\text { Information college of Shanxi } \\
\text { agricultural university }\end{array}$ & 0.518 & 1 & 0.518 \\
\hline $\begin{array}{l}\text { College of modern arts and } \\
\text { sciences, Shanxi normal university }\end{array}$ & 0.654 & 1 & 0.654 \\
\hline Shanxi business college & 0.518 & 1 & 0.518 \\
\hline Taiyuan institute of technology & 0.418 & 0.553 & 0.756 \\
\hline $\begin{array}{l}\text { Shanxi institute of engineering and } \\
\text { technology }\end{array}$ & 0.57 & 1 & 0.57 \\
\hline Shanxi energy college & 0.518 & 1 & 0.518 \\
\hline Mean & 0.64 & 0.856 & 0.765 \\
\hline
\end{tabular}

Scale efficiency is mainly used to measure the impact of university scale on the efficiency of scientific research. When scale efficiency reaches an effective scale, it indicates that the university has reached the optimal scale in the existing situation of resource allocation. From the analysis and research, it can be concluded that the average size efficiency of the 27 undergraduate universities in Shanxi Province is 0.765 . Meanwhile, two of the 27 universities in Shanxi Province achieved the optimal scale efficiency, indicating that these 2 universities are in the optimal scale utilization. The remaining 24 colleges and universities are in the state of increasing scale efficiency, and one is in the state of decreasing scale, that is, the utilization efficiency of resources is low, which indicates that it is not suitable to expand the scale under the current level of resource input, increase resource input, and should focus on strengthening the utilization rate of resources. In terms of the scores of non-effective units of scale efficiency, there is a big difference in the scores of 25 non-effective units.

The pure technical efficiency index represents the impact of management and technology on the scientific research efficiency of colleges and universities. From the analysis and research results, it can be concluded that the average value of pure technical efficiency of 27 colleges and universities is 0.856, among which 14 colleges and universities' scientific research activities show that the Pure technical efficiency, and
13 colleges and universities show that the technical efficiency is invalid. The level of pure technical efficiency represents a large gap in scientific research efficiency caused by the difference in management and technology. On the whole, the difference of pure technical efficiency of undergraduate universities in Shanxi Province is small and the situation is good. In addition, compared with scale efficiency, the average score of pure technical efficiency of undergraduate universities in Shanxi Province is higher than that of scale efficiency. That is to say, the pure technical efficiency of current undergraduate universities in Shanxi Province has little impact on comprehensive efficiency compared with scale efficiency.

Comprehensive efficiency measures and evaluates the efficiency of scientific research activities in colleges and universities as a whole. The average comprehensive efficiency of scientific research activities of 27 colleges and universities in Shanxi Province is 0.64. From the perspective of comprehensive efficiency index, the overall efficiency of scientific research activities of undergraduate colleges and universities in Shanxi Province is relatively good. Two of the 27 universities are relatively effective units. Among the units that fail to achieve technical efficiency, 4 colleges and universities have a comprehensive efficiency lower than 0.5 , and 9 colleges and universities have a technical efficiency higher than 0.5. It can be seen that, compared with the pure technical efficiency, the scale efficiency of Shanxi undergraduate colleges and universities has a greater impact on the comprehensive efficiency. To improve the comprehensive efficiency of Shanxi undergraduate colleges and universities, it is imperative to strengthen the reasonable allocation of scientific research resources of Shanxi undergraduate colleges and universities.

\section{COUNTERMEASURES AND SUGgestions FOR IMPROVING THE EFFICIENCY OF SCIENTIFIC RESEARCH IN COLLEGES AND UNIVERSITIES}

\section{A. Improving the organizational structure and expanding the talent team}

Shanxi Province is located in the middle of China, because of rich coal resources, has been developing the coal economy for many years and some neglect education. The attraction to talents is not obvious, and the scientific research development level is relatively backward. Expanding talent has two aspects: one is the expansion of quantity; the other is the expansion of quality. You can't have one without the other. Both the improvement in quantity and quality are inseparable from the strong support of Shanxi provincial government and organization. In order to attract talents to Shanxi Province, Shanxi provincial government needs to provide some preferential policies for the imported talents.

\section{B. Further rational allocation of scientific research resources in universities}

Scientific research without material security can only cook without rice and water without a source. The problem of educational resources in Shanxi Province has always been an important factor affecting the development of colleges and universities in Shanxi Province. At present, the development 
level of colleges and universities in Shanxi Province is uneven, which requires the Shanxi provincial government to allocate scientific research resources reasonably to ensure that all colleges and universities in Shanxi Province are in a reasonable state of scale.

\section{Scientific research in undergraduate universities should have "characteristics"}

From the perspective of Shanxi government, Shanxi government should coordinate the development of colleges and universities from the overall deployment, and provide special resources support according to different research directions. Let each university have its own characteristics, let each university give play to their own characteristics, their own expertise research focus in-depth research. In this way, all the universities in Shanxi Province have their own advantages and their own advantageous disciplines. Thus, resources are saved and not wasted. In terms of scientific research, resources in the same research field are invested centrally, without repeated or scattered input, so as to achieve the maximum scientific research scale benefit of Shanxi undergraduate universities.

\section{Establishing a scientific and dynamic evaluation mechanism of university efficiency}

The establishment of a scientific evaluation mechanism is to provide feedback on the real-time scientific research efficiency of Shanxi undergraduate universities. These feedbacks are valuable to both the government and the universities themselves. From the point of view of the government, according to the real-time dynamic feedback, it can adjust the resource input to each university. Universities with low efficiency or decreasing scale efficiency can reduce resource input, while those with high efficiency or increasing scale can increase input appropriately. This real-time dynamic evaluation result can also be used as a reference standard for the government to evaluate the scientific research situation of universities and how much resources are invested. In addition, from the perspective of colleges and universities, they can refer to their own situation according to the real-time and dynamic evaluation results, and adjust their scientific research management appropriately according to the evaluation results. If the evaluation result of scientific research efficiency is poor, universities need to adjust their scientific research management arrangement. If the evaluation result of scientific research efficiency is good, it can be used as the standard for continuous development.

\section{CONCLUSION}

This paper evaluates the efficiency of 27 universities in Shanxi Province. According to the research results, the difference of pure technical efficiency is small, but the difference of scale efficiency is obvious. At the same time, the scientific research efficiency of Shanxi undergraduate universities is greatly affected by the scale efficiency, and the low scientific research efficiency of Shanxi undergraduate universities is mainly affected by the low scale efficiency of Shanxi undergraduate universities. Therefore, it can be seen that whether the scale efficiency of Shanxi undergraduate universities can be improved restricts the future development of scientific research of Shanxi undergraduate universities. Therefore, it is imperative to improve the scale efficiency of Shanxi undergraduate universities. One of the reasons for low scale efficiency is that resources are not used effectively and scientific research achievements are few. Therefore, this paper puts forward the following suggestions to improve the efficiency of scientific research in colleges and universities in Shanxi Province: expand the talent team, make rational use of resources, give full play to the "characteristics" of colleges and universities, and establish an evaluation system.

\section{ACKNOWLEDGMENT}

The authors gratefully acknowledge Education and teaching reform research project of Shanxi university of finance and economics: A study on the influencing factors and improvement of students' satisfaction in the flipped classroom, no. 2018216, 2019 "flipped classroom" teaching model reform project of Shanxi university of finance and economics: Management Science,no.201906.

\section{REFERENCES}

[1] Jun CAI, Peifeng Ma. Evaluation of the internal driving force of scientific research in universities based on DEA model [J]. Research on education finance and accounting, 2018, 29(05):60-66.

[2] Ying Wang, Yanping Liu. An Empirical Study on the Evaluation of Scientific Research Efficiency of University Management Schools Based on DEA Method[J].Journal of Beijing Jiao tong University (Social Science Edition), 2007(04):43-47.

[3] Xiaohua Song, Chengxiang Fu. Research university scientific research performance in our country and its influencing factors, based on an empirical analysis of the related data of colleges and universities directly under the ministry of education $[\mathrm{J} / \mathrm{OL}]$. University education management, 2019 (05): 1-10 [2019-09-06].

[4] Lianbao Qiao. Comprehensive efficiency evaluation of scientific research and teaching in "985" universities based on the joint DEA model [J]. Scientific research management, 2015, 36(S1):210-215

[5] Huiqin Zhang, Tianyi Shang. Comparative analysis of innovation efficiency of scientific research in universities--based on panel data of 30 provinces in China [J]. Scientific research management, 2015, 36(S1):181-186

[6] Tianzuo Liu, Hang Xu. Research input-output performance of scientific research in universities in different regions of China and its influencing factors -- an empirical study based on DEA-Tobit model [J]. Science and technology management research, 2008, 38(13):113-118. 